\title{
Preliminary Evaluation of a Reform of Methods to Teach Pharmaceutical Polymer Materials Science to a Class of Diverse Majors
}

\author{
Zhongbing Liu, Yan Lin, Zhirong Zhong* \\ Department of Pharmaceutical Sciences, School of Pharmacy, Southwest Medical University, Luzhou, Sichuan, CHINA.
}

\begin{abstract}
Objective: Pharmaceutical polymer materials science is a new discipline that integrates the fields of materials science, polymer chemistry, polymer physics and pharmaceutical preparation and it is an indispensable part of modern pharmacy. This study aimed to improve the quality of teaching pharmaceutical polymer materials science to a class of mixed majors. Materials and Methods: We reformed the teaching content and methods of the pharmaceutical polymer materials course at Southwest University and implemented strategies to enhance exchange between teachers and students. In redesigning the teaching content, we made use of multiple teaching methods including example-teaching, heuristic teaching, problem-based learning, comparative teaching, interactive teaching and the flipped classroom. Results: Reforming teaching methods improved teaching quality and student interest in the course. Conclusion: The reformed teaching program in this study was effective at improving student interest, initiative and enthusiasm for learning. The strategies used in this reform should be promoted and applied in the teaching of other courses.
\end{abstract}

Key words: Pharmaceutical polymer materials science, Teaching reform, Teaching method, Teaching quality, Multi-professional classroom.

\section{INTRODUCTION}

Polymer materials have a long history in the pharmaceutical field. Humans in ancient times began to use the natural polymer materials such as starch, cellulose, polysaccharides and proteins. Natural polymers could be used as prescription additives. Polymer compounds are also called macromolecules. The concept of a macromolecule, long chain structures formed by polymerization of small molecules linked by covalent bonds, was first introduced by the German scientist H. Staudinger in 1920 and experimentally verified by W. Carothers in 1929 . Staudinger went on to show that macromolecular weight was related to solution viscosity and won the Nobel Prize in Chemistry in 1953. Since then, the field of polymer science has progressed rapidly, leading to the development of pharmaceutical polymer materials that have had a profound impact on healthcare. ${ }^{1}$ Pharmaceutical polymer materials science integrates diverse fields including materials science, polymer chemistry, polymer physics and pharmaceutical preparation and is an indispensable part of modern pharmacy. ${ }^{2}$

To meet with the needs of pharmaceutical industry, our school offers courses in pharmaceutical polymer materials as part of three undergraduate majors: pharmacy, traditional Chinese medicine and clinical pharmacy. These courses cover the source, preparation, structure, properties and applications of pharmaceutical polymer materials, with the aim of discovering new polymer materials and methods for drug formulations. Our course is set in the first semester of the senior year and aims to complement existing pharmacy courses. The aim of the course is to teach students the basic theories of
Submission Date: 29-01-2019; Revision Date: 29-03-2019; Accepted Date: 26-07-2019

DOI: 10.5530/ijper.53.4.122 Correspondence:

Prof. Zhirong Zhong, Department of Pharmaceutical Sciences, School of Pharmacy, Southwest Medical University, Luzhou, Sichuan- 646000, CHINA. Phone: +8613982796280 E-mail: zhongzhirong@126. com

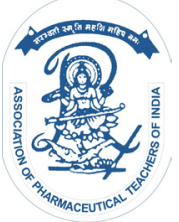

www.ijper.org 
pharmaceutical polymer materials and their applications in drug research, including general pharmaceutical, sustained-release and controlled-release preparations; new drug delivery systems; and how to perform research. ${ }^{3}$ The pharmaceutical polymer materials science course has strong theoretical and practical components. We identified several problems in teaching this course. First, students in pharmacy, traditional Chinese medicine and clinical pharmacy generally began the course with a foundation in mathematics, chemistry, materials science and mechanics that was insufficient to understand course materials. As this course is not taught until the first semester of the senior year, students from different majors enter the course with very different backgrounds but no knowledge of the concepts of polymer materials. Secondly, there were insufficient supporting materials for teaching. This course was launched only recently in national medical colleges and is offered in only a few schools. Few textbooks and reference books cover polymer materials science and most teachers do not have sufficient teaching experience in this subject. There are no other supporting courses and most textbooks do not have corresponding experimental courses. Thirdly, most schools use the traditional classroom teaching method, which is useful for teaching abstract principles and concepts but is not effective in helping students understand the practical applications of pharmaceutical polymer materials in pharmacy. Due to the lack of practical experience, students often do not perform well in combining theory with practice. Students in course at our school have also reported boredom because teachers use only one teaching mode and have poor teaching skills. As this is a multidisciplinary class with many students, it is difficult to establish mutual communication and emotional connection between teachers and students. ${ }^{4}$

To improve the teaching efficacy of pharmaceutical polymer materials science in practice and to align it with professional requirements, we reformed the teaching methods for this course and discuss the effects on teaching and learning efficacy in the classroom.

\section{MATERIALS AND METHODS}

\section{Design of teaching content}

This study was reviewed and approved by the Institutional Human Ethics Committee of Southwest Medical University (permit no. 20160600). We designed the teaching content to be at a higher level than the available textbooks. Teaching content was selected according to the requirements of the syllabus, focusing on the basic concepts and principles of pharmaceutical polymer materials and the structure, synthesis, modification, physicochemical properties and preparation of commonly used pharmaceutical polymer materials. We used these principles to explain and study the application of polymer materials in conventional preparations, sustained release preparations, controlled-release preparations and targeted drug delivery systems.

We found it was necessary to supplement teaching materials with the latest research on newly developed polymer materials and their applications in drug development and production in order to expand the students' depth and breadth of theoretical knowledge. For example, the cereal-derived protein gliadin has limited use in food due to its poor water solubility and cannot be directly used by the human body. However, gliadin can be widely used in plastics, coatings, inks, adhesives, chewing gum and fiber. Recent studies have also shown that gliadin can be used in nanoformers. ${ }^{4}$ The cerealderived protein zein can be used as an enteric coating material in pharmaceutical preparations. Therefore, we included information about these cereal-derived proteins in the teaching materials.

In designing the teaching content, we also took into account connections with existing pharmacy courses. We described pharmaceutical polymer materials using pharmaceutical dosage terms with which students were already familiar. For example, when teaching about polymers as capsule materials, students were required to review the classification and preparation methods of capsules that have already been covered in the pharmacy course. This allowed students to review previous knowledge while also studying new knowledge, making the content of the course easier and more focused. Teachers were also encouraged to incorporate their own research and experiences into the course. This teaching method enriches the content and raises the teaching level, improves interest and learning, cultivates a sense of innovation and creativity and guides students towards proactive thinking.

\section{Enhancing exchange between teachers and students}

An important part of classroom teaching is allowing teachers and students to share thoughts, emotions and experiences. It is a process in which teachers and students agree, share and advance together to achieve the common goal of teaching and learning. Due to the reduced teaching time and a lack of practical classrooms, there were few opportunities for teachers to meet with students. However, we encouraged instructors to use time before and during the class to communicate and share professional knowledge as well as educational and life experiences with students. We proposed that 
this could help eliminate rejection of the course caused by unfamiliarity with the teacher and course materials through the so-called 'love me, love my dog' effect. Teachers were encouraged to use software tools such as the WeChat platform which was widely used in China for the internal communication to teach and communicate with students outside of class. Our rationale was that this additional teacher-student interaction could promote self-learning, thinking and creativity in students. Teachers in turn could also better understand the thoughts and opinions of their students and receive feedback to improve their teaching methods and quality.

\section{Using flexible teaching methods}

The pharmaceutical polymer materials course introduces a wide variety of commonly-used polymer materials. This course is closely related to pharmacy and teachers need to be well-prepared beforehand. We recommended that teachers have a certain teaching skill and organizational ability. Teachers were also encouraged to carefully prepare and arrange the teaching content according to the syllabus, summarize comparisons of different pharmaceutical polymer materials and simplify complicated problems. Teachers were also encouraged to use examples to help students learn actively and enjoy learning. The teaching methods we used to reform this course are described below.

\section{Example-teaching method}

The example-teaching method can enhance students' perceptual knowledge and improve teaching and learning by allowing students to take initiative and brainstorm ideas. Representative examples are given in the pharmaceutical polymer materials textbook. ${ }^{5}$

Examples of pharmaceutical polymer materials can be included from daily life (Table 1). Common everyday examples can also be used to explain abstract conceptsfor example, the concept of surfactants can be taught using soybeans, which contain phospholipids. Phospholipids are zwitterionic surfactants, which act as an emulsifier when grinding soymilk. Surfactant emulsification and protein gelation can also be taught through the process of tofu production from soybeans. Tofu is produced by immersing soybeans in water, followed by refining, slag removal and heating to obtain a protein colloid. An electrolyte solution (such as a salt halide) is then added to neutralize the colloid particles, coagulating the protein and separating it from the water. This everyday example demonstrates a practical application of an abstract concept, which helps facilitate students' memory and mastery, guides them to think positively and exercise their thinking ability and stimulates interest
Table 1: Common everyday examples of

pharmaceutical polymer materials.

\begin{tabular}{|c|c|}
\hline Pharmaceutical polymer materials & Common examples \\
\hline chitosan & surgical sutures \\
\hline gelatin & hollow capsules \\
\hline $\begin{array}{c}\text { methyl methacrylate, hydroxyethyl } \\
\text { methacrylate, glyceryl methacrylate }\end{array}$ & contact lenses \\
\hline polycarbonate & plastic bottles \\
\hline polyethylene, polypropylene & $\begin{array}{c}\text { carbonated beverage } \\
\text { bottles }\end{array}$ \\
\hline polyvinyl chloride & sewage pipes \\
\hline povidone iodine & disinfectant \\
\hline rubber & tires \\
\hline sodium carboxymethyl cellulose & thick milk \\
\hline $\begin{array}{c}\text { sodium carboxymethyl cellulose, gum } \\
\text { Arabic }\end{array}$ & rice, flour, corn \\
\hline starch & hand cream \\
\hline $\begin{array}{c}\text { vaseline, hexadecanoic acid isopropyl lanolin } \\
\text { ester }\end{array}$ & \\
\hline
\end{tabular}

in learning, which in turn enhances learning ability and efficiency.

Students may know that polymer materials such as polyester and nylon are commonly used in clothing fabrics, but they may be unfamiliar with and interested in how waterproof, sun-protective or self-heating fabrics are prepared. Teachers can also use videos to teach students how to use thickeners such as sodium alginate, agar, gelatin and carrageenan to make homemade jelly and pudding. These examples connect polymer materials with clothing, food and shelter, so that students can see their relevance to everyday life, thereby stimulating more interest in the course.

Teachers can also use negative events in the pharmaceutical industry as examples so that students can understand the importance of pharmaceutical excipients. For example, in 2017 Merck updated the formula of Euthyrox ${ }^{\circledR}$, a drug used to treat hypothyroidism, but the new product was found to cause serious adverse reactions despite no change in the key active ingredient. It was eventually found that this was caused by changing the polymer material in the excipients from lactose to mannitol and anhydrous citric acid, which unexpectedly increased the absorption rate of key ingredients of levothyroxine sodium.

Polymer materials also occupy a pivotal position in pharmaceutical packaging. Most of the polymer materials currently used for pharmaceutical packaging fall within five categories: Polyethylene, polypropylene, Polyvinyl Chloride (PVC), polystyrene or polyester. PVC is used as a pharmaceutical packaging film and usually contains 
added plasticizer to increase transparency and flexibility. Teachers can teach the importance of plasticizer toxicity using the plasticizer contamination of juice and beverages in Taiwan in 2011 and the liquor plasticizer scandal in China in 2012 as examples. In these incidents, the plasticizer Diethylhexyl phthalate (DEHP) was illegally added to food as an emulsifier and stabilizer. DEHP acts as an artificial hormone and can harm reproduction in males and accelerate puberty in females. Long-term intake can also lead to liver cancer. This example can be used to teach students the importance of pharmaceutical packaging material additives and their potential toxicity. ${ }^{6}$ Polycarbonate (PC) is also a useful example to teach toxicity. PC is widely used in daily life because it shows excellent electrical insulation, elongation, high strength, dimensional stability, resistance to heat and cold and chemical inertness. PC is also inexpensive and can increase transparency and drop resistance. However, Bisphenol Propane (BPA) is used as a raw material in the synthesis of PC and unconverted BPA can be found in almost all PC materials. Residual BPA can precipitate in food and beverages when heated and if ingested can disrupt metabolism, infant development, immunity and even lead to cancer. High temperatures accelerate BPA release from PC materials and so it is recommended that PC cups should not be heated, exposed directly to sunlight or used to hold hot water. These examples can be used to educate students about the toxicity of residual monomers and how to reduce toxicity.

\section{Heuristic teaching method}

Developing a student's desire for knowledge and ability to solve practical problems often begins with posing a problem. The process of learning is one of constantly discovering, analyzing and solving problems. Heuristic teaching can motivate students to take initiative, think independently and exercise their logical thinking skills, thereby allowing them to analyze and solve problems.

In the pharmaceutical polymer materials course, we encouraged teachers to use a WeChat group to set questions before class and allow students to think by themselves. For example, when teaching the characteristics of starch and cellulose, students could be asked "If starch is structurally similar to cellulose, why can cattle eat grass but not humans?" This question could guide students to think and understand that while the overall structure of starch is similar to that of cellulose and the molecular formulas are identical, starch is linked by $\alpha-1,4$ glycosidic bonds, while cellulose is linked by $\beta-1,4$ glycosidic bonds. As humans only possess an enzyme that hydrolyzes $\alpha-1,4$ glycosidic bonds but lack an enzyme to hydrolyze $\beta-1,4$ glycosidic bonds, cellulose cannot be absorbed by humans.

Through heuristic teaching, students can learn to use textbook knowledge for solving practical problems, as well as increase the breadth and depth of their theoretical knowledge, thereby building a solid foundation for future work in research.

\section{Problem-based learning (PBL) method}

PBL is a popular teaching method in which teachers lead the class using a problem-oriented strategy and students discuss in groups. The teacher then summarizes the discussion results and helps students develop a deeper understanding of the significance of the problems discussed. ${ }^{7}$ Problem-based learning is different from the traditional teaching mode in that it is based on the problem, with the students as the main actors and the teacher as the guide. It promotes systematic and comprehensive learning of the problems and deep understanding of concepts. It also lets students fully exercise their initiative. Teachers set questions before class so that students can prepare answers beforehand for discussion. Questions could include:

- What are the applications of protein polymers in daily life?

- What are the applications of bio-adhesive materials in pharmacy?

- What are the properties and applications of chitin and chitosan?

- What is the difference between animal and plant sources for the polymer materials of hollow capsules?

- What are the properties and applications of pregelatinized starch?

- How many types of natural polysaccharide materials are there?

To motivate students to explore, teachers can also set topics based on questions raised by students, conduct group discussions, encourage students to present their own opinions and guide students to think about problems from multiple perspectives and levels. This strategy can promote an active and open classroom atmosphere, relieve the teaching workload, allow students to engage in active discussion and minimize boredom.

An important part of this teaching method is teaching students how to think about problems and ask valuable questions. The theme can be set using recent events in society that cause major concerns or questions raised by students. Group discussions are conducted and then each team selects a representative to speak. This encour- 
ages students to form their own questions and opinions and think about problems from multiple angles.

\section{Comparative teaching method}

The comparative teaching method could reduce repetition and enable students to form rigorous logical thinking ability and improve their ability to summarize and memorize. Many different polymer materials are covered in this course, some of which have similar names and are easy to confuse. In order to help students, distinguish different materials, teachers can help students conduct a contrastive analysis of polymer materials with their existing knowledge to help them understand new knowledge. For example, the concept of primary, secondary and tertiary structures in pharmaceutical polymer materials can be difficult for students to understand. However, students should already be familiar with primary, secondary and tertiary structures of proteins after the pre-requisite biochemistry course. Therefore, they can be compared as follows. Polymers are composed of many repeating structural units and the tertiary polymer structure consists of both the short- and long-range structure and the aggregate structure of the polymer chain. ${ }^{8}$ The short-range structure is the most basic polymer unit and can be compared to a chain link. It includes the chemical composition, configuration, structure and copolymer sequence, in which the chemical composition of the main chain determines the classification of the polymer. The secondary structure, also known as the remote structure, refers to the structure of the entire molecular chain. The tertiary structure or super molecular structure, is the aggregate structure of a polymer. It refers to the arrangement and stacking of molecular chains in a polymer, which is a group behavior. Tertiary structure includes the polymer's crystal structure, amorphous structure, liquid crystal structure and orientation structure. ${ }^{9}$

Proteins are special biopolymers that have primary, secondary, tertiary and quaternary structure. The primary structure is the most basic and refers to the order of amino acids in the peptide chain, which also determines the higher-order structure of the protein. Spatial structure includes secondary, tertiary and quaternary structure. Secondary structure refers to the folding and coiling of the main polypeptide chain. ${ }^{10}$ Depending on the secondary structure, side chains can form secondary interactions such as hydrogen bonds, van der Waals forces, hydrophobic interactions and ionic bonds. The polypeptide chain is then further curled, folded and coiled in three-dimensional space to form a more complex specific conformation, which is the tertiary structure. Quaternary structure refers to the linking of multiple folded polypeptide chains via secondary bonds to form a unique spatial structure. Proteins formed by one polypeptide chain only have primary, secondary and tertiary structures, while proteins formed by two or more polypeptide chains can have a quaternary structure. ${ }^{11}$ Proteins are a large class of biological macromolecules with specific structures and biological functions. The primary, secondary and tertiary structures of a polymer chain are not equivalent to those of a protein, but there are many similarities. This similarity can be analyzed in the case of the configuration and conformation of polymers. Configuration refers to the proximal structure of the polymer chain, while the conformation refers to the distal structure. Both configuration and conformation characterize the polymer molecular structure in three-dimensional space. ${ }^{12}$ In comparison, proteins are composed of component molecules (amino acids) and the order of the components is called the primary structure; the local spatial arrangement of the skeleton carbon atoms in the polypeptide chain is called the secondary structure; the spatial arrangement of the side chain carbon atoms is called a tertiary structure; while the combined structure of multiple chains is referred to as quaternary structure. The secondary, tertiary and quaternary protein structures, which refer to the spatial arrangement of the polypeptide chain, can be compared to polymer conformations. Using this comparison, students can more easily understand the concepts of short-and long-range structure and aggregate states in polymers.

\section{Interactive teaching method}

Electronic devices such as smart phones and tablets are widely used by student and provide an effective medium for convenient and efficient communication between teachers and students. We implemented three new modes of teaching on the WeChat platform based on the PBL teaching method. The first, which we called "one-to-one" teaching, involves establishment of WeChat or QQ friendship between teachers and students to allow teachers to give guidance and explanations for questions raised by students in daily learning. However, teachers often find the common questions/ issues that are the same for many students using the "one-to-one" method. In this situation, teachers can use the "one-to-many" teaching mode as shown in Figure 1 The third method is "many-to-many" teaching, where experts in pharmaceutical polymer materials are invited to conduct a "many-to-many" discussion on a problem or phenomenon.

Using these teaching methods on platforms such as WeChat and QQ, teachers can provide feedback on 


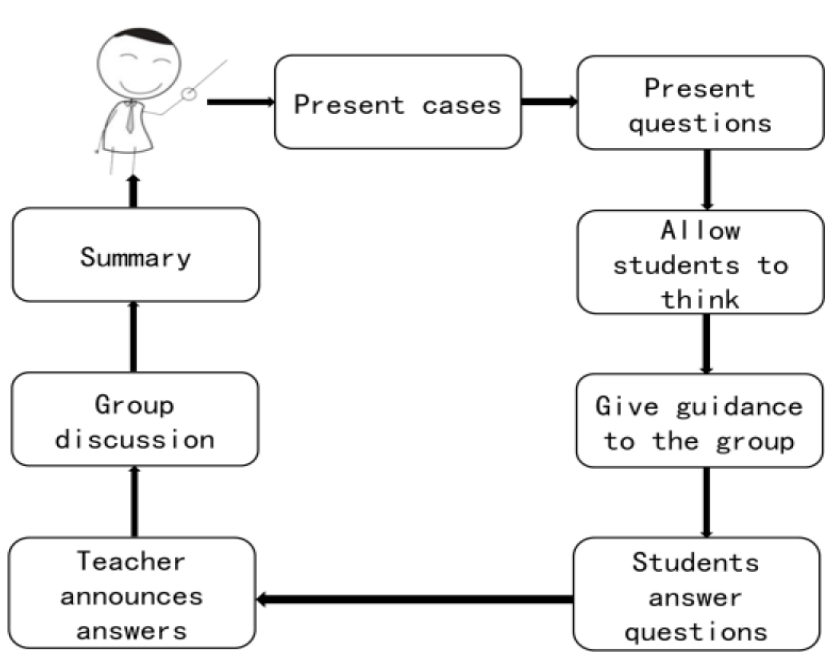

Figure 1: The "one-to-many" teaching mode.

questions from students in a timely manner even outside of class. Discussions can be conducted in real time, in a flexible way. This method has the potential to show concepts in a vivid and concrete form, reduce the complexity of learning and establish good interactions and communication between teachers and students, thereby deepening the students' understanding and enthusiasm for learning.

\section{Flipped classroom}

Flipped classroom is a special teaching model in which teachers provide videos as the main learning resource. Teachers upload teaching and experimental videos to the WeChat platform in advance and students are instructed to view and study them before class. Teachers and students then work together in the classroom to answer questions collaboratively and interactively. ${ }^{13}$ This wellknown model reverses the traditional teaching method and has become popular in the global education field. ${ }^{14}$

\section{RESULTS AND DISCUSSION}

In this research article, we describe the reform of teaching methods for pharmaceutical polymer material science for students from multiple majors. The reformed course greatly increased the students' interest in learning and improved the teaching quality of pharmaceutical polymer materials science. In the final exam, the average scores significantly increased from 75 to 90 , showing the success of this reforming.

In practice, teachers always applied multiple teaching methods. For example, when teaching about polysaccharides and natural pharmaceutical polymer materials like pectin and gum Arabic, an experimental video about making jelly was sent to the WeChat group before class for students to watch in advance. This meant that the students already had a visual image to follow in class, which is more conducive to classroom teaching. Multimedia resources such as text, pictures, voice and video can all be used. This method was convenient, novel and free. Moreover, it was effective at attracting the students' attention and can achieve the same teaching effect as the flipped classroom method. This new extracurricular learning method can be accessed anywhere and anytime. The back-end database provided by the network teaching platform can also be used to view message statistics through the analysis and message interaction functions. ${ }^{15}$ This could allow teachers to determine which content the students have read, the number of times they watched a video, the time spent reading and the questions sent by the student. Such statistics could provide a record for student evaluation and a new platform for combining innovative and professional teaching. ${ }^{16}$

All the teaching methods described above can be applied flexibly. They utilize the existing knowledge of students coming from different majors, allows them to participate in discussions together and express their opinions to achieve the common goal of learning.

\section{CONCLUSION}

Implementation of example-based, heuristic, PBL, comparative, interactive and flipped classroom teaching can stimulate student interest in learning and improve teaching quality in pharmaceutical polymer materials science.

\section{ACKNOWLEDGEMENT}

The authors are thankful for support from the Education and Teaching Reform Research Project of Southwest Medical University (JG2017079 and 2012126).

\section{CONFLICT OF INTEREST}

The authors declare no conflict of interest.

\section{ABBREVIATIONS}

BPA: Bisphenol propane; DEHP: Diethylhexyl phthalate; PBL: Problem-based Learning; PC: Polycarbonate; PVC: Polyvinyl chloride.

\section{REFERENCES}

1. Miao JL, Chen XB, Wang CJ. Study on teaching content and teaching method of polymer science in pharmaceutics. Guangzhou Chemical Industry. 2017;45(11):212-3.

2. Deng SX, Li G, Wu Q. Research on the reform of the teaching mode of polymer in pharmaceutics. Guangdong Chemical Industry. 2014;41(10):170-1.

3. Yu FB, Tong L, Gao JX. Application of role exchange teaching method in the teaching of medicinal polymer materials. Studies of Trace Elements and Health. 2016;33(2):89-90. 
4. Hu K, Mcclements DJ. Fabrication of surfactant-stabilized zein nanoparticles: A pH modulated antisolvent precipitation method. Food Res Int. 2014;64:329-35.

5. Gao F, Chen YZ, Lou KY. Improvement of students' activity in the teaching of polymer science in pharmaceutics. Pharmacy Education. 2016;32(2):47-50.

6. Li W. A preliminary study on the teaching reform of medicinal polymer materials. Health Vocational Education. 2012;30(15):31-2.

7. Strohfeldt K, Khutoryanskaya $\mathrm{O}$. Using problem-based learning in a chemistry practical class for pharmacy students and engaging them with feedback. Am J Pharm Educ. 2015;79(9):141.

8. Zhu SN. Polymer chain structure. Engineering Plastics Application. $1981 ;(2): 3-4$.

9. Zhao K. Teaching analysis of polymer chain structure. Science and Technology Economic Guide. 2016;(29):174.

10. Liu LY. Preliminary study on the teaching of protein molecular structure. Yinshan Academic Journal. 1998;(1):108-11.

11. Jiang $L$. Talking about the understanding of protein denaturation and its variants. Chemistry Teaching and Learning. 2017;(6):9-12.

\section{PICTORIAL ABSTRACT}

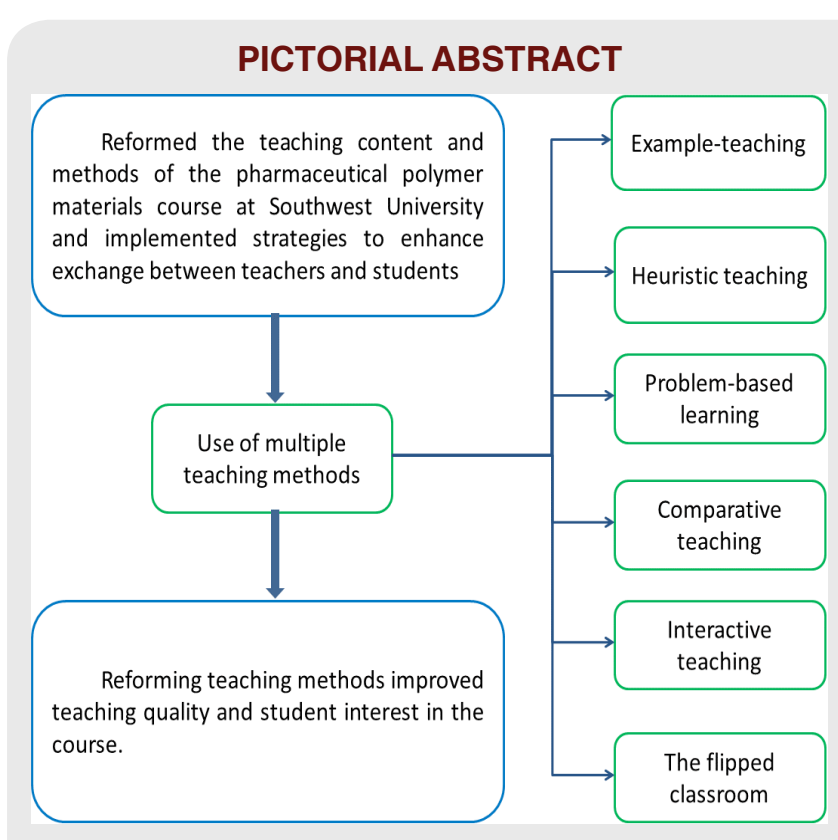

12. Zhang GX. On the configuration and conformation of protein molecules(I) distinction between configuration and conformation. Journal of Hebei University. 1981;(1):68-74.

13. White PJ, Naidu S, Yuriev E, Short JL, McLaughlin JE, Larson IC. Student engagement with a flipped classroom teaching design affects pharmacology examination performance in a manner dependent on question type. Am J Pharm Educ. 2017;81(9):5931.

14. $\mathrm{Li} \mathrm{YH}$, Geng $\mathrm{YH}, \mathrm{Yu} \mathrm{XL}$, Li BB. Application research of flipping classroom teaching mode in the course of biology teaching in normal universities. Education Teaching Forum. 2018;39:191-2.

15. Len J, Xu XJ. Experiences and trends of educational innovations supported by information technology-an interview with prof. Christopher dede. Open Education Research. 2014;20(4):4-8.

16. Wu SM, Zuo YY, Meng Q. Exploring flipped classroom model based on wechat and wechat public perform. Chinese Medical Education Technology. 2015;29(1):44-7.

\section{SUMMARY}

The reformed teaching program in this study was effective at improving student interest, initiative, and enthusiasm for learning. The strategies used in this reform could be promoted and applied in the teaching of other courses.

\section{About Authors}

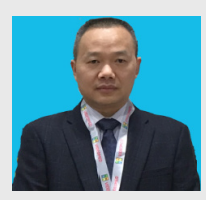

Zhongbing Liu is a teacher of Southwest Medical University. His research interest focuses on the optimization of the pharmaceutical formulations.

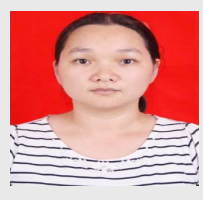

Yan Lin is an Assistant Professor at the Southwest Medical University. She is an experienced researcher in new drug development, mainly focuses on pharmaceutical preparations.

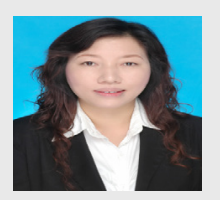

Zhirong Zhong is a professor at the Faculty of Pharmacy, Southwest Medical University. She got her Master degree and Ph.D in Pharmaceutics from Sichuan University. She has more than 10 years' experience in Pharmacy teaching. Additionally, she focuses on development of novel drug delivery system and drug-targeting delivery.

Cite this article: Liu Z, Lin Y, Zhong Z. Preliminary Evaluation of a Reform of Methods to Teach Pharmaceutical Polymer Materials Science to a Class of Diverse Majors. Indian J of Pharmaceutical Education and Research. $2019 ; 53(4): 613-9$. 